\title{
The Relationship between Breastfeeding Position and Level of Postpartum Fatigue
}

\author{
Wafaa Abed El-Hamed Rashad*, Wafaa Mohamad Alarousy**
}

\begin{abstract}
A quasi-experimental study was conducted at Postpartum Unit of King Fahd University Hospital in Al-Khobar, Kingdome of Saudi Arabia to investigate the relationship between breastfeeding position and level of postpartum fatigue. The study sample consisted of 100 postpartum women who accepted to participate in the study. Level of fatigue was initially assessed before breastfeeding the baby using the lowa fatigue scale, then the study subjects were randomly divided into two groups, group I $(n=50)$ began breastfeeding their newborns for 10 minutes in high Fowler's position on the bed with back supported and a pillow under the arm to support the newborn and to reduce the tension on the muscle and a pillow under the newborn to raise him to sufficient height to reach the breast easily. After the 10 minutes, they were assisted to reposition themselves to side lying position with the arm raised on the head, comfortably supported, and the newborn lying supported on side so can grasp the breast easily, and the mother feeding the newborn for another 10 minutes. Group II ( $n=50)$ started breastfeeding their newborn in side lying position for 10 minutes and then shifted to high Fowler's position and breastfed for another 10 minutes. Each subject was instructed to mark the lowa fatigue scale after breastfeeding in each position to determine the level of fatigue. Side lying position, for those during breastfeeding was the most comfortable position for the whole studied women aged less than 25 years old, were pregnant for less than three times, had less than three living children, received antenatal care, and who did not receive any information about breastfeeding. Increased emphasis on the advantages of the side lying position for breastfeeding can easily be included in routine postpartum nursing practice with minimal risk and cost.
\end{abstract}

\section{INTRODUCTION}

The postpartum period covers a critical transitional time for a woman, her newborn, and her family, on a physiological, emotional, and social level. Researches have shown that $44 \%$ to $95 \%$ of postpartum mothers in the United
States experience fatigue, i.e., the postpartum fatigue is a common problem. ${ }^{(1,2)}$ The condition is viewed as a complex phenomenon related to physiological, psychological, and situational factors and experienced as unpleasant symptoms which incorporate

\footnotetext{
*Maternity \&Gynecologic Nursing, University of Alexandria

${ }^{* *}$ Pediatric Nursing, University of Alexandria
} 
total body feelings, ranging from tiredness to exhaustion, creating an unrelenting overall condition which interferes with individual's ability to function to their normal capacity. Persistent postpartum fatigue has been associated with postpartum depression which is known to interfere with the development of the mother-child relationship and can also result in child maltreatment especially with the new mothers. ${ }^{(3-6)}$ Grdner and Campble $^{(7)}$ suggested that breastfeeding is one of the contributing factors to postpartum fatigue. Also the literature shows that the common reason nursing mothers give for discontinuation of breastfeeding is fatigue. ${ }^{(8,9)}$

Breastfeeding provides ideal nutrition for the infant; the American Academy of Pediatrics, the American Dietetic Association, and World Health Organization recommend exclusive breastfeeding for at least the first 4-6 months of life. The benefits of breastfeeding to both infant and mother are well known and include superior nutritional content of human breast milk in an easily digestible forms, enhanced immunologic status of the newborn that protects them from infection, strengthening of the infant-mother attachment, delayed return of ovulation, and economic savings. (10 -12) The WHO Healthy People 2010 Objectives include goals of having $75 \%$ of mothers breastfeed their infants in the early postpartum period, and $50 \%$ continuing to breastfeed at least 6 months. ${ }^{(9-12)}$

In Ontario and Canada, there is some evidence that although the majority of women initiate breastfeeding, $15 \%-20 \%$ have discontinued by one month, approximately $30 \%$ have discontinued by two months and $70 \%$ have discontinued by six months. ${ }^{(8)}$ In Melbourne, Australia, although the data suggested that at hospital discharge, breastfeeding rate are close to the Commonwealth target initiation rate of $75 \%$, state figures revealed that breastfeeding rates had declined rapidly after discharge. At discharge from hospital 
$73.9 \%$ of new mothers who were breastfeeding had decreased to $69.5 \%$ at two weeks, $53.9 \%$ at three months and $40 \%$ at six months. ${ }^{(13)}$

Breastfeeding is often associated in women's mind as contributing to the feelings of overall perceived fatigue and many women indicate that they have ceased breastfeeding because of fatigue. Reasons for decreased breast feeding have not been extensively elaborated. ${ }^{(8,14-}$ 16) Milligan et al., ${ }^{(14)}$ recommended the side lying position while breastfeeding as a comfortable position, while Reeder et al.,(18) reported that some mothers prefer to sit up to breastfeed their babies while others improvise position that works well for them and their newborn. The puerperal women may need help finding a comfortable position while breastfeeding, often, in their eagerness to get the newborn on the breast; they become tense and assume uncomfortable positions, although they assure the nurse that they are comfortable.
Many hours of mother's time, day and night for many months, will be spent breastfeeding her baby. She should be supported and enabled to accomplish it with skill, confidence, and pleasure. The nurse should assist the breastfeeding mothers in experimenting with various positions during breastfeeding in order to decrease the sense of fatigue. Maternity and pediatric nurses are concerned about ways that progress can be made towards provision of comfort and prevention of fatigue and promotion of a successful breastfeeding, particularly due to current decreasing breastfeeding rate. Therefore, the aim of this study was to investigate the relationship between breastfeeding position and level of postpartum fatigue.

Key words: postpartum fatigue, breastfeeding position, fatigue scale MATERIAL AND METHODS

\section{Study design \& Setting}

This study is a quasi-experimental study conducted in the postpartum unit of King Fahd University Hospital in Al-Khobar, 
Saudi Arabia. This hospital was selected because research is one of its main goals to improve the quality of care rendered.

\section{Subjects}

A convenient sample of 100 postpartum women who accepted to participate in the study were selected from the previously mentioned setting according to the following criteria: postpartum mothers having normal vaginal delivery, normal breast with protruded nipple, having non-complicated labour \& delivery, free from any postpartum complications or associated disease, and gave birth to full term newborn with no congenital anomalies interfering with breastfeeding.

\section{Tools}

Two tools were used for data collection. First, a specially designed interview schedule was developed by the researchers based on literature review and used to collect data about the general characteristics of the study subjects such as: age, education, occupation; obstetric characteristics such as gravidity, parity,...etc. Second, lowa Fatigue Scale $e^{(17)}$

was used to assess the level of fatigue during breastfeeding in two different positions. The scale is composed of 11 items with 5 point scale designed to measure four domains: cognitive, fatigue, energy and productivity. Each subject was instructed to choose one of the five possible responses that are closest to how she felt with the statement during breastfeeding in each position. The total score was calculated by adding together the score of each item. The score 30-39 indicated fatigue and score 40 - 55 indicated severe fatigue. The scale was translated into Arabic language by the researchers, tested and verified by bilingual assessors specialized in the field. These were experts from the Maternity and Gynaecologic Nursing Department and Paediatrics Nursing Departments in College of Nursing, King Faisal University.

\section{Methods of data collection}


1. Official permission was obtained to carry out the study from the previously mentioned setting.

2. A pilot study was carried out on 5 breastfeeding women out of the sample to ascertain the relevance of the questions and to detect any further problems peculiar to the sequences and clarity of the tool. Then the questionnaire sheet was reconstructed and made ready for use.

3. Each postpartum woman was interviewed during the early postpartum period (2-3 days) to explain the purpose of the study, how to mark the lowa Fatigue Scale, and to collect the necessary data.

4. The level of fatigue was initially assessed before breastfeeding the baby using the lowa Fatigue Scale to determine the level of fatigue before breastfeeding.

5. The study subjects were randomly divided into two groups. Each woman was given a sealed paper, which contained the group allocation.

6. Group I $(\mathrm{n}=50)$ began breastfeeding their newborns for 10 minutes in high Fowler's position on the bed with back supported and a pillow under the arm to support the newborn and to reduce the tension on the muscle and a pillow under the newborn to raise him to sufficient high to reach the breast easily. After the 10 minutes they were assisted to reposition themselves to side lying position with the arm raised on the head, comfortably supported, and the newborn lying supported on side so can grasp the breast easily, and the mother feedd the newborn for 10 minutes.

7. Group II $(n=50)$ started to breastfeed their newborns in side lying position for 10 minutes and then shifted to high Fowler's position and breastfed for 10 minutes.

8. Each subject was instructed to mark the lowa Fatigue Scale after 
breastfeeding in each position to determine the level of fatigue.

9. The researcher completed each interview in approximately 40 to 50 minutes. The study was done over a period of 3 months from June 2007 to August 2007.

\section{Statistical analysis:}

Data was collected, coded, and transferred into a specially designed format for computer feeding. Following data entry, checking and verification processes were carried out to avoid any errors during data entry. Frequency analysis, crosstabulation, and manual revision were all used to detect any errors. The SPSS program, version 12 was utilized for both data presentation and statistical analysis of the results. The following statistical measures were used:

a) Descriptive measures included: Count, percentage, arithmetic mean, and standard deviation.

b) Statistical tests included: McNemar chi square, Pearson chi square, student $t$ test, paired t test, repeated measures ANOVA, and stepwise multiple regression. The level of significance selected for this study was $p$ less than 0.05

\section{RESULTS}

Table (1) showed that $36 \%$ and $24 \%$ of the studied women aged less than 25 years in group I and group II, respectively. Slightly more than one half of group I and group II (54.0\%) had secondary school education, and slightly less than threefourths in group I and group II ( $70 \%$ and $74 \%$, respectively) were housewives. There were no statistically significant differences between the two groups in their socio-demographic characteristics.

Table (2) indicated that, $54 \%$ of group I and $48 \%$ of group II were pregnant for less than three times, $40 \%$ of group I and $52 \%$ of group II gave birth for three times or more, and $66 \%$ and $48 \%$ of group I and group II, respectively had less than three children. The table also showed that the majority of group I (96.0\% and $86.0 \%)$ 
and group II (90.0\% and $80.0 \%)$ received antenatal care and had more than 4 antenatal visits respectively. Regarding the sources of knowledge about breastfeeding, written materials were the most common source of knowledge among group I (38.0\%) and group II (46.0\%). No statistically significant differences between the two groups were detected in their obstetric characteristics.

Table (3) shows distribution of the studied women according to the level of fatigue. It was found that in group one, $16.0 \%$ had expressed severe fatigue before breastfeeding their babies. This percentage had increased to $40.0 \%$ during feeding in Fowler's position and decreased to $10.0 \%$ during feeding in side lying position. In group two, 42.0\% had expresses severe fatigue before breastfeeding their babies, this percentage increased to $46.0 \%$ while breastfeeding in Fowler's position and decreased to $8.0 \%$ in side lying position. The difference was statistically significant among the two groups regarding breastfeeding positions $\left(\mathrm{Mc} \chi^{2}\right.$ 12.03, $\left.\mathrm{p}=0.001\right)$

Table (4) shows the relation between women's characteristics and level of fatigue. Statistical significant differences were found between the two groups regarding the level of fatigue in the two different position in respect to age $(p<0.001)$, gavidity $(p<0.001$ and 0.0148$)$, parity $(p<0.001$ and 0.0416$)$, and number of living children as $p<0.001$ and 0.0337 . The results also showed a significant effect for the two positions on the level of fatigue in group one and two with respect to number of antenatal visits $(p=0.0178$ and $\mathrm{p}<0.001$ ) and receiving information about breastfeeding as $p<0.001$.

Table (5) reveals significant predictors of fatigue resulting from breastfeeding among women in different positions. Young age, higher number of children, and receiving antenatal care significantly predicted fatigue score during postpartum period. Higher number of children and receiving antenatal care proved to be 
significant predictors of fatigue in the breastfeeding in Fowler's position, while receiving antenatal care and not receiving breastfeeding information were the significant predictors of fatigue in breastfeeding in the side lying position.

\section{DISCUSSION}

Fatigue in the postpartum period has the capacity to interfere with the women's ability to attain full functional status. It adversely affects not only the women's quality of life, but also that of her family. For two decades, women have been ranking fatigue as a major concern during the postpartum period. Causes of fatigue include physiological, psychological and situational factors. Positioning during breastfeeding represents one of the physiologic factors that need to be investigated. In the present study, an attempt was made to explore the relationship between breastfeeding position and level of postpartum fatigue. It is an everlasting important area of interest which may have a greatest impact on initiation and continuation of breastfeeding.

Fatigue during postpartum period had a high prevalence rate, Ko $(2004)^{(2)}$ and others $^{(19,20)}$

reported that $44.0 \%$ to $95.0 \%$ of postpartum women experience fatigue. Similarly, the results of the present study indicated that $58.0 \%$ of the studied women were complaining of severe fatigue. This percentage is not surprising because the postpartum period is a very critical transitional phase marked by dramatic physical changes and strong emotions.

Although, Novak and Broom (1999)(21) reported that breastfeeding in a sitting position is more comfortable to women, the results of the present study revealed that almost about one half of the studied women in either group were complaining of severe fatigue while breastfeeding their babies in Fowler's position. This is compared to only small proportions of those who were breastfeeding in side lying position experience severe fatigue. This 
result is supported by Milligan et al., (1996) ${ }^{(14)}$ who reported that, the use of side lying position for breastfeeding was associated with significantly less fatigue than the sitting position. This may be due to the fact that side lying position enables mother to rest more completely than is possible if she is sitting up.

The results of the present study presented that the majority of the studied women in group one and group two found the side lying position during breastfeeding was most comfortable compared to sitting position. This result agrees with the Troy $(2003)^{(4)}$. This result could be explained by the fact that the study is carried out in early postpartum period (2-3 days) which is the critical transitional period and during this period the woman needs to rest increase and the side lying position help her to have some rest during breastfeeding her baby.

The results of the present study indicated that, young maternal age was found to be significant predictor of fatigue score. This is supported by Troy and Dalagas (1997) ${ }^{(22)}$ and Wambach ${ }^{(16)}$. However, in the study of Troy and Dalagas the study sample was primiparous. Primipara are young who have no experience in breastfeeding and they may need help finding a comfortable position while breastfeeding. However, this result is not online with Lee and Zaffke $(1999)^{(23)}$ who reported that younger age women were more likely to experience fatigue than older women. The results of the current study showed that higher number of living children and receiving antenatal care were found to be a predictor of postpartum fatigue. Also, higher number of children and receiving antenatal care significantly predicted fatigue score during breastfeeding in Fowler's position, while receiving antenatal care and not receiving information about breastfeeding significantly predicted fatigue during breastfeeding in side lying position. However, no studies are available either to confirm or to negate such findings because postpartum fatigue was not identified as a separate entity in the classic maternity textbooks until very recently. ${ }^{(4)}$ Furthermore, according to $\mathrm{WHO}^{(1)}$ only scanty research data are available on needs of women and babies in postpartum period. Moreover, in developing \& developed 
countries women needs during this period and those of their newborns have been too often eclipsed by the attention given to pregnancy and birth. Such an eclipse ignores that fact that the majority of maternal deaths and disabilities occur during this period.

The antecedents of postpartum fatigue and measures to reduce it have barely been discussed in literature, nor have they been empirically investigated. This reflects the needs for further studies to add to understand fatigue during postpartum period and how it can be prevented or ameliorated which could reflect positively on initiation and continuation of breastfeeding.

\section{CONCLUSION AND RECOMMENDATIONS}

The importance of the study reflected in relative fatigue score related to types of breastfeeding position. Studied women experienced considerably less fatigue during breastfeeding in side lying. position rather than the Fowler's positionThese findings are important for nursing practices. It is recommended that increased emphasis on the advantages of the side lying position for breastfeeding can easily be included in routine postpartum nursing practice with minimal risk or cost.

Table 1: General characteristics of the studied women

\begin{tabular}{|c|c|c|c|c|c|}
\hline \multirow{2}{*}{$\begin{array}{c}\text { General } \\
\text { Characteristics }\end{array}$} & \multicolumn{2}{|c|}{ Group I $(n=50)$} & \multicolumn{2}{|c|}{ Group II (n=50) } & \multirow{2}{*}{$\begin{array}{c}\chi^{2} \\
(\mathrm{P})\end{array}$} \\
\hline & No. & $\%$ & No. & $\%$ & \\
\hline \multicolumn{6}{|l|}{ Age } \\
\hline$<25$ & 18 & 36.0 & 12 & 24.0 & 7.298 \\
\hline $25-$ & 15 & 30.0 & 8 & 16.0 & [0.063] \\
\hline $30-$ & 9 & 18.0 & 13 & 26.0 & \\
\hline $35+$ & 8 & 16.0 & 17 & 34.0 & \\
\hline \multicolumn{6}{|l|}{ Education } \\
\hline Illiterate & 2 & 4.0 & 4 & 8.0 & 4.619 \\
\hline Basic & 7 & 14.0 & 12 & 24.0 & [0.329] \\
\hline Secondary & 27 & 54.0 & 27 & 54.0 & \\
\hline University & 14 & 28.0 & 7 & 14.0 & \\
\hline $\begin{array}{l}\text { Occupation } \\
\text { Housewife } \\
\text { Student } \\
\text { Working }\end{array}$ & $\begin{array}{c}35 \\
7 \\
8\end{array}$ & $\begin{array}{l}70.0 \\
14.0 \\
16.0\end{array}$ & $\begin{array}{c}37 \\
5 \\
8\end{array}$ & $\begin{array}{l}74.0 \\
10.0 \\
16.0\end{array}$ & $\begin{array}{c}0.389 \\
{[0.823]}\end{array}$ \\
\hline
\end{tabular}


Table 2: Obstetric characteristics of the studied women

\begin{tabular}{|c|c|c|c|c|c|}
\hline \multirow{2}{*}{$\begin{array}{c}\text { Obstetric } \\
\text { Characteristics }\end{array}$} & \multicolumn{2}{|c|}{ Group I $(n=50)$} & \multicolumn{2}{|c|}{ Group II $(n=50)$} & \multirow{2}{*}{$\begin{array}{c}\chi^{2} \\
\mathbf{( P )}\end{array}$} \\
\hline & No. & $\%$ & No. & $\%$ & \\
\hline \multicolumn{6}{|l|}{ Gravidity } \\
\hline$<3$ & 27 & 54.0 & 24 & 48.0 & \multirow{2}{*}{$\begin{array}{c}0.360 \\
{[0.548]}\end{array}$} \\
\hline $3+$ & 23 & 46.0 & 26 & 52.0 & \\
\hline \multicolumn{6}{|l|}{ Parity } \\
\hline$<3$ & 30 & 60.0 & 24 & 48.0 & \multirow{2}{*}{$\begin{array}{c}1.449 \\
{[0.229]}\end{array}$} \\
\hline $3+$ & 20 & 40.0 & 26 & 52.0 & \\
\hline \multicolumn{6}{|l|}{ Abortion } \\
\hline None & 35 & 70.0 & 34 & 68.0 & \multirow{3}{*}{$\begin{array}{c}5.785 \\
{[0.055]}\end{array}$} \\
\hline 1 & 12 & 24.0 & 6 & 12.0 & \\
\hline $2+$ & 3 & 6.0 & 10 & 20.0 & \\
\hline \multicolumn{6}{|l|}{ Living children } \\
\hline$<3$ & 33 & 66.0 & 24 & 48.0 & \multirow{2}{*}{$\begin{array}{c}3.305 \\
{[0.069]}\end{array}$} \\
\hline $3+$ & 17 & 34.0 & 26 & 52.0 & \\
\hline \multicolumn{6}{|l|}{ Receiving knowledge } \\
\hline No & 2 & 4.0 & 5 & 10.0 & \multirow{2}{*}{$\begin{array}{c}1.382 \\
{[0.240]}\end{array}$} \\
\hline Yes & 48 & 96.0 & 45 & 90.0 & \\
\hline $\begin{array}{c}\text { Antenatal visits } \\
<4\end{array}$ & 7 & 14.0 & 10 & 20.0 & \multirow{2}{*}{$\begin{array}{c}0.638 \\
{[0.424]}\end{array}$} \\
\hline $4+$ & 43 & 86.0 & 40 & 80.0 & \\
\hline \multirow{3}{*}{$\begin{array}{c}\text { Knowledge source } \\
\text { Antenatal sessions } \\
\text { Booklets } \\
\text { Relatives / friends }\end{array}$} & 17 & 34.0 & 8 & 16.0 & \multirow{3}{*}{$\begin{array}{c}4.320^{*} \\
(0.038) \\
0.657(0.418) \\
0.0(1.00)\end{array}$} \\
\hline & 19 & 38.0 & 23 & 46.0 & \\
\hline & 15 & 30.0 & 15 & 30.0 & \\
\hline
\end{tabular}

- $\quad$ Significant, $P<0.05$.

- $\quad$ ** More than one answer 


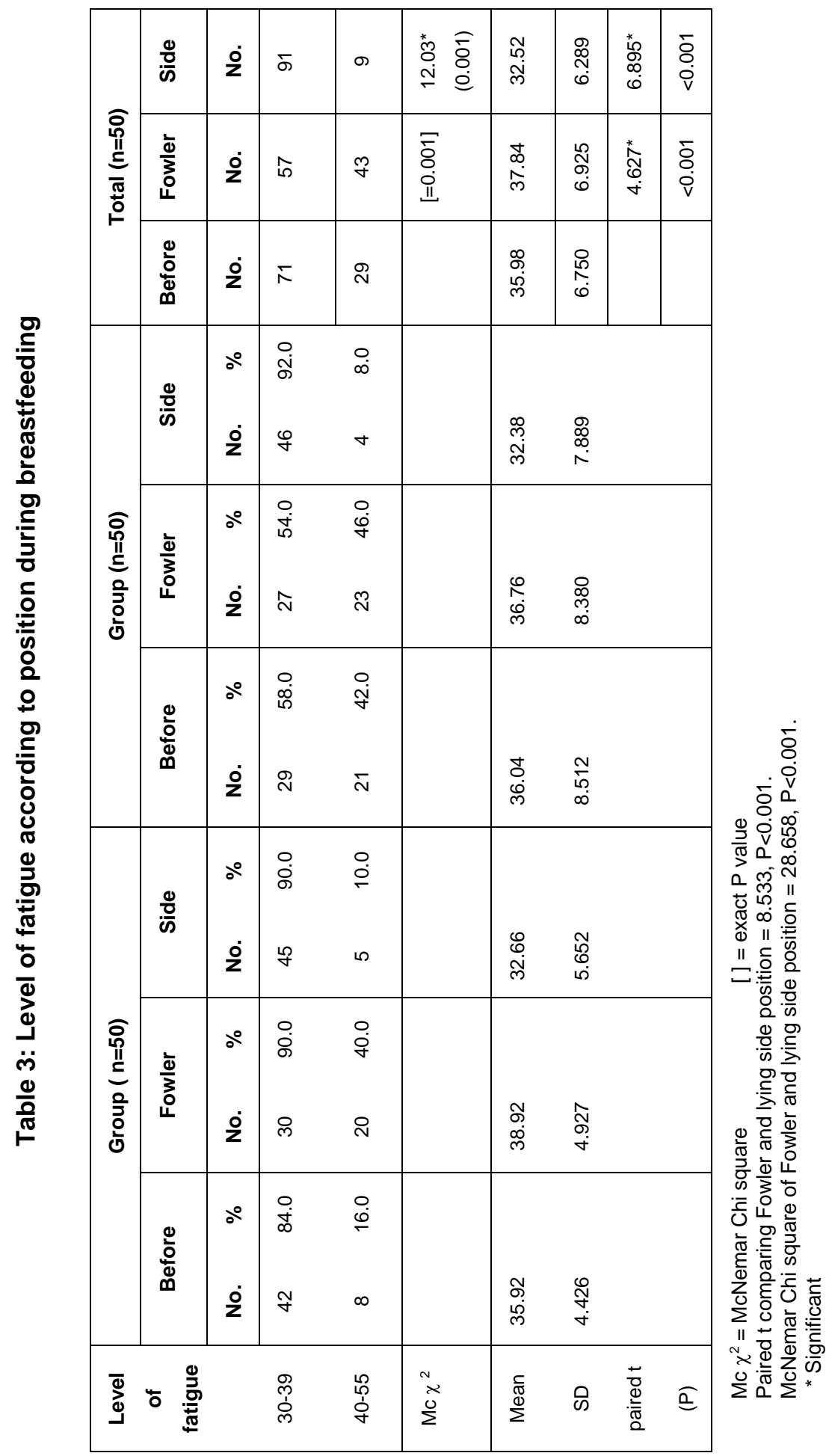




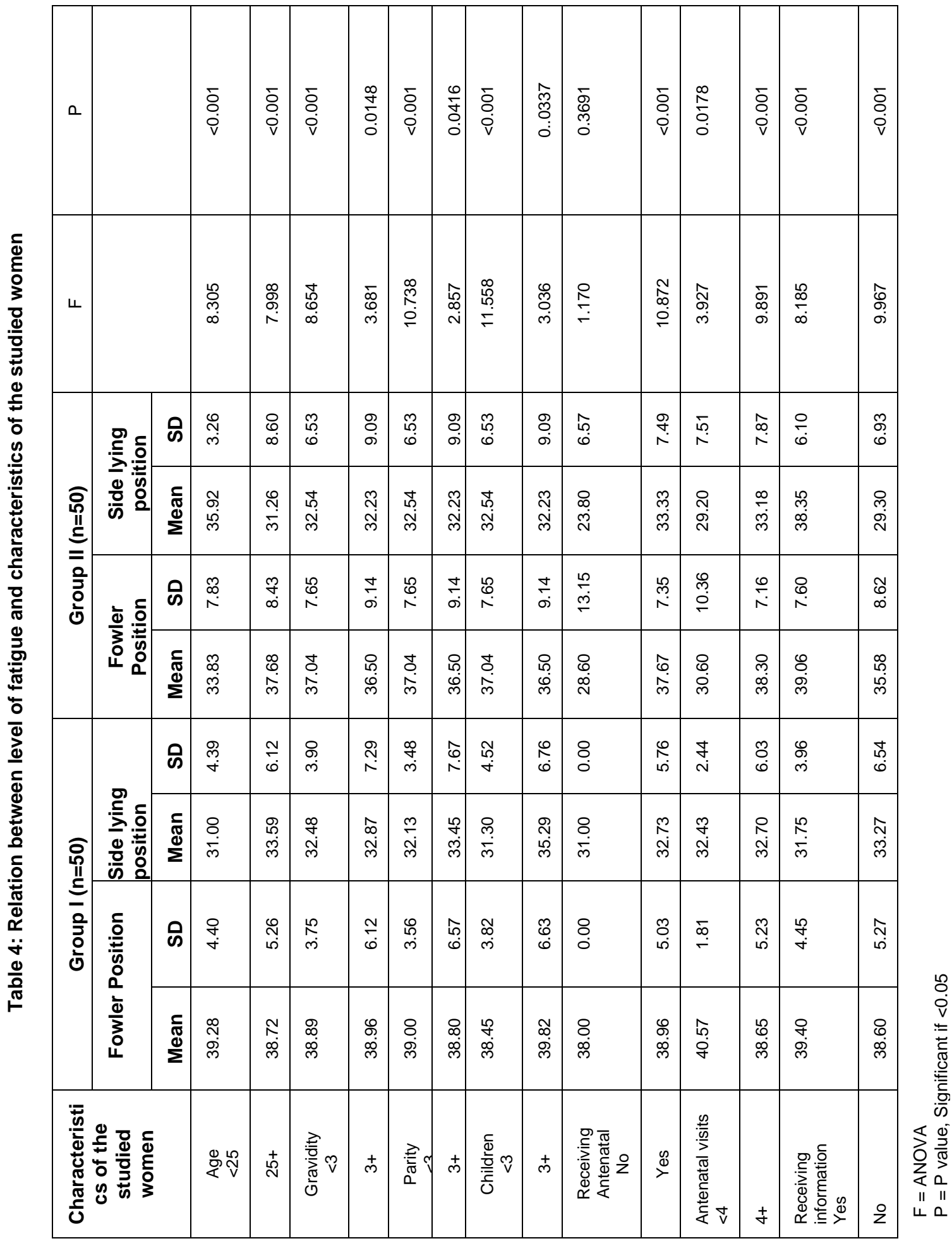


Table 5: Significant factors predicting fatigue resulting from breastfeeding at different positions using stepwise multiple linear regression model

\begin{tabular}{|l|l|l|l|}
\hline \multirow{2}{*}{ Factor } & & \multicolumn{2}{|c|}{ Position } \\
\cline { 2 - 4 } & Before & Fowler & Side lying \\
\hline Constant & 31.570 & 27.831 & 28.784 \\
\hline Age & -0.312 & - & - \\
\hline No. of living children & 1.315 & 0.620 & - \\
\hline Receiving antenatal care & 10.039 & 8.689 & 6.00 \\
\hline Receiving breastfeeding information & - & - & -2.927 \\
\hline
\end{tabular}

\section{REFERENCES}

1. WHO. Safe Motherhood: postpartum care of mother and newborn: A practical Guide. Report of Technical Working Group, WHO. 1998. 1-2.

2. Ko Y. Postpartum fatigue. Hu LI Za Zhi. 2004 Dec;51(6):75-9

3. Bozoky I, Corwin EJ. Fatigue as a predictor of postpartum depression. J Obstet Gynecol Neonatal Nurs. 2002 Jul-Aug; 31(4): 436-43

4. Troy NW. Is the significance of postpartum fatigue being overlooked in the lives of women? MCN, The American Journal of Maternal and Child Nursing. 2003 July - August; 28(4):252-7

5. Beck CT. The effect of postpartum depression on maternal-infant interaction: A Meta Analysis. Nursing Research. 1995; 44: 298-304.

6. Milgrom J. Mother-infant interaction in postpartum depression: Anearly intervention program. The Australian Journal of Advanced Nursing. 1994; 11(4): 29-36

7. Gardner DL, Campdell B. Assessing postpartum fatigue. MCN, The American Journal of Maternal and Child Nursing. 1991; 16: 264-6.

8. Ontario Public Health Association (OPHA). Breastfeeding. A position paper adopted at the 1993 OPHA Annual Igeneral Meeting. [Cited 1993]. Available from: www.opha.on.ca

9. Schilling JA. Straight $A^{\prime}$ 's in paediatric nursing. Philadelphia; Lippincott Williams \& Wilkins; 2004

10. Hochenberry MJ. Wong's Essentials of pediatric nursing. $7^{\text {th }}$ ed. United States of America: Elsevier Mosby; 2005.
11. Wight NE. Management of common breastfeeding issues. Pediatr Clin North Am. 2001; 48(2): 321-44.

12. Hillenbrand KM, Larsen PG. Effect of educational intervention about breastfeeding on knowledge, confidence and behaviours of paediatric resident physicians. Paediatrics. 2002; 110(5):e59.

13. Forster $\mathrm{D}$, McLachlan $\mathrm{H}$, Lumley $\mathrm{J}$, Beanland $\mathrm{C}$, Waldenstrom $\mathrm{U}$, Harries $\mathrm{H}$, et al. Attachment to the breast and family attitudes to breastfeeding. The effect of breastfeeding education in the middle of pregnancy on the initiation and duration of breastfeeding: a randomised controlled trial [ISRCTN21556494]. BMC Pregnancy and Childbirth 2003; 3:5. [Cited 2003]. Available from: http://www.biomedcentral.com/1472393/3/5

14. Milligan RA, Flenniken PM, Pugh LC. Positioning intervension to minimize fatigue in breastfeeding women. Applied Nursing Research. 1996; 9: 67-70.

15. Callahan S, Sejourne N, Denis A. Fatigue and breastfeeding: An inevitable partnership? Journal of Human Lactation. 2006; 22(2):182-7.

16. Wambach KA. Maternal fatigue In breastfeeding primipara during the first nine weeks postpartum. J Hum Lact. 1998 Sep; 14(3):219-29.

17. Hart A, Bentler S, Watson D. Measuring fatigue severity in primary care patients. Journal of Psychometric Research. 2003, 54(6): 515-21.

18. Reeder JS, Martin LL, Griffin KD, Maternity Nursing: Family, newborn, and women's health care. $18^{\text {th }}$ ed, Philadelphia, New York: Lippincott; 1997. 
19. Cheng CY. Continuing education module: Postpartum maternal health care in the United States: A critical review. The Journal of Perinatal Education. 2006;15(3), 34-42.

20. Ansara D, Cohen M, Gallop R, Schei B. Predictors of women's physical health problems after childbirth. Journal of Psychosomatic Obstetrics and Gynaecology. 2005; 26: 115-25.

21. Novak JC, Broom BL. Ingallas \& Saleron's maternal and child health nursing. $9^{\text {th }}$ ed. Mosby Company; 1999. $p$ 401-411

22. Troy NW, Dalagas-Pelish P. The natural evolution of postpartum fatigue among group of primiparous women. Clin Nurs Res. 1997; May;6(2):126-39.

23. Lee KA, Zaffke ME. Longitudinal changes in fatigue and energy during pregnancy and the postpartum period. Journal of Obstetric \& Gynecologic and Neonatal Nursing.1999; 28:183-191. 
